Association for Information Systems AIS Electronic Library (AISeL)

ICIS 1980 Proceedings

International Conference on Information Systems

1980

\title{
MEASUREMENT AS AN MIS FOUNDATION
}

\author{
Richard O. Mason \\ University of Southern California \\ E. Burton Swanson \\ University of California, Los Angeles
}

Follow this and additional works at: http://aisel.aisnet.org/icis 1980

\section{Recommended Citation}

Mason, Richard O. and Swanson, E. Burton, "MEASUREMENT AS AN MIS FOUNDATION" (1980). ICIS 1980 Proceedings. 12. http://aisel.aisnet.org/icis1980/12

This material is brought to you by the International Conference on Information Systems (ICIS) at AIS Electronic Library (AISeL). It has been accepted for inclusion in ICIS 1980 Proceedings by an authorized administrator of AIS Electronic Library (AISeL). For more information, please contact elibrary@aisnet.org. 


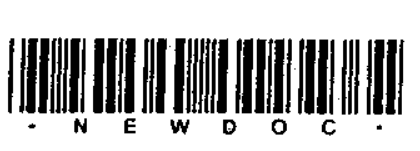




\title{
MEASUREMENT AS AN MIS FOUNDATION
}

\author{
RICHARD O. MASON
}

School of Business Administration University of Southern Cali fornia

\author{
E. BURTON SWANSON
}

Graduate School of Management

University of Cali fornia, Los Angeles

\section{INTRODUCTION}

Measurement is an essential feature of every management information system (MIS) of which we are aware, though it has been little studied in this context. The MIS data base is typically replete with measures of various kinds, but the measurement properties of MIS data have as yet received little attention from practitioners and theoreticians alike. It is our view that this inattention is unfortunate. Measurement deserves recognition as one of the most important of MIS foundations.

While measurement is currently well recognized as a component of scientific methodology, it is less well appreciated for its various roles in management. (Mason and Swanson, 1979) During the last six years, the authors have collaborated on a study project designed to articulate these management aspects from an MIS perspective. A progress report on this undertaking, in the form of a book of readings, will soon appear. (Mason and Swanson, in press) In the present paper, we content ourselves with a brief summary of some of the most important aspects of measurement as an MIS foundation.

\section{FOUNDATIONAL ASPECTS}

Seven aspects of measurement are of particular importance in terms of MIS foundation. These are summarized in Figure 1. Each will be discussed briefly in turn.

\section{SCIENTIFIC AND TECHNICAL CHARACTERISTICS}

The subject of measurement is usually discussed in a scientific and technical context. (See, for example, Kerlinger, 1973). Among the properties of measures frequently mentioned in this context are: (i) scale type - e.g. nominal, ordinal, interval, or ratio; (ii) reliability -often interpreted as the consistency of results in repeated applications under a standard set of circumstances; (iii) sensitivity - the ability to discriminate along the dimension of concern; (iv) objectivity -- the degree to which results differ according to the "subjective" perceptions of the measurer; and (v) validity -- the elusive notion of whether the measure measures what it is supposed to measure.

scientific and technical characteristics of measures are an important aspect of measurement for management decision making. For example, in developing a measure of organizational productivity, issues of scale type, reliability, sensitivity, objectivity, and validity may all be of critical significance. However, other issues, beyond those of traditional scientific and technical concern, are of equal importance, as the sections which follow attempt to indicate.

\section{DESIGN CHOICES}

Churchman (1967) has identified four design choices which are intrinsic to the measurement process, for both scientific and managerial applications. The nature of each of these choices requires that trade-offs in cost-effectiveness be made. The first choice, that of language, involves weighing the benefits of language refinement with the costs of understandability on the part of the using population. An example is the decision to use multiple measures of the money supply in the U.S., a refinement in language which must bear the social costs of understanding involved. A second choice is that of specification, a decision which weighs breadth of application against the costs of generalizing the measurement process. Here an example would be a decision to use a common measure of productivity for firms in multiple industries. A third design choice is that of standardization, i.e., the determination of the set of circumstances under which measures are to be generated, or to which measures are to be adjusted. 


\section{Figure 1}

Aspects of Measurement as an MIS Foundation

(1) Scientific and technical characteristics

scale type, reliability, sensitivity, objectivity, validity

(2) Design choices

language, specification, standardization, accuracy and control

(3) Information and decision support suggestive, predictive, decisive, systemic

(4) Managerial functions

Attention-directing, problemsolving, scorecard-keeping

(5) Organization focus

organizational, individual, societal

(6) Information system origin

data gathering, data processing, inquiring and deciding

(7) Behavioral dimensions

measurer, measuree, user of measures 
Here, costs of standardization must be balanced against the benefits of comparability achieved. The development of accounting standards provides a commonplace example, in this case. Finally, the choice of the appropriate level of accuracy and control in measurement must consider a similar tradeoff of costs and benefits. The design of a management control system in an orqanizational hierarchy involves such trade-offs, for example.

The design of any MIs requires that the four choices identified by Churchman be intelligently made.

\section{INFORMATION AND DECISION SUPPORT}

Measures for management may further be classified according to four levels of information and decision support. (Churchman, 1968) At the first level, termed suggestive, minimal assumptions are made about the user's information needs. An illustration, in the context of a marketing problem, might be, "Sales last quarter were down 158 over the same quarter a year ago." At the second level, termed predictive, the measures make a statement about the contigent future, assuming certain choice alternatives for the decision maker. An illustration here would be, "Sales may be increased next year by $25 \%$ over this year, by adoption of the new marketing plan." Decisive measures constitute the third level of support, and provide closure to the decision making situation, implying a choice. An illustration, in the context of the marketing problem, might be," The internal rate of return on implementation of the new marketing plan, over the next five years, is expected to be 308 . "At the fourth level of support, the systemic level, the manager's problem situation is placed in an enlarged context, which provides a challenge to "premature" closure. An illustration here might be, "Marketing is the third most important problem area for our organization, a fter research and product development, and production quality control."

One of the most important design issues for any M.I.S. is the determination of the appropriate level(s) of information and decision support to be provided in the measurements reported to management.

\section{MANAGERIAL FUNCTIONS}

Measures may also be classified according to the managerial functions supported by information. These functions include attention-directing, problemsolving, and scorecard-keeping (March and
Simon, 1958). Attention-directing provides an answer to the question. "What problems shall I look into?" A common measurement for this purpose is the cost accounting variance, for example. problem-solving answers the question, "What course of action is better?" Here, a cost-benefit ratio provides an illustrative example. Scorecard-keeping is based upon the question, "How well am I doing?" The periodic reporting of profit and production figures provide classical examples of measurement for this purpose.

Measures in a management information system may support any or all of the functions described. An important MIS design problem is the choice of the appropriate mix of managerial functions to be supported, and the associated set of measures which will achieve this end.

\section{ORGANIZATIONAL FOCUS}

Measurements for management decision also have an organizational focus. Three levels of measures are of special importance in this regard: (i) measures of organizational attributes, e.g. productivity, profitability, market leadership; (ii) measures of individual attributes of persons, e.g., aptitude, attitude, skill level, job performance; and (iii) measures of societal characteristics, e.g $\therefore$ population, employment, education, environmental quality. The imperative to measure at each of these three levels can be derived in terms of the systems theory of Churchman (1971), as we have argued. (Mason and Swanson, 1979)

Measurement problems typically differ in certain ways, at each of the levels of focus. At the organizational level, the search is often for a "bottom ine" indicator of performance, in terms of which all organizational activity is ultimately rationalized. Questions of organizational purpose are fundamental here. At the individual level, predictive measurement of role performance is of particular interest. Here, psychological measurement techniques are often of use. At the societal level, the need is to provide both information about the organization's environment for the organization, and information about organizations in aggregate for social decision making. Here, techniques for generating social indicators predominate.

The typical MIS is focused at one or more of the three levels indicated. An important design issue is the determination of the appropriate focus, and the associated choice of measurements to implement this focus. 


\section{INFORMATION SYSTEM ORIGIN}

An information system consists of three generic functional components: (i) a data gathering function; (ii) a data processing function; and (iii) an inquiring and deciding function. Measurement may occur as part of each. To illustrate, consider an information system which supports the admissions office of a university. Among the data gathered on an applicant would be measures of scholastic abilities such as those provided by the Educational Testing Service (ETS). In processing the data gathered, a predictive measure of the applicant's likely performance as a student might further be generated. Finally, in deciding upon admission, the applicants might be ranked. Thus, it is seen that measurement may permeate each of an information system's basic generic functions.

The design of any MIS requires that the origin of its measurements be appropriately distributed across its three basic functions.

\section{BEHAVIORAL DIMENSIONS}

Individual persons are involved in measurement for management decision in three roles: (i) as measurer; (ii) as measuree, either directly or indirectly; (iii) as a user of measures. Behavior in each role is a crucial aspect of measurement for management decision, shaping and shaped by both the measure and its interpretations.

Employee appraisal systems present a straight forward illustration of the behavioral dimensions. In rating employees, the "personal equation" of the rater commonly plays an important role, and this is communicated explicitly or implicitly, to the individual rated. The individual rated adapts his or her behavior in turn. Users of the ratings, for example, personnel departments, further communicate additional aspects of the measurements by means of their decisions, and both measurers and measurees again adapt their behaviors accordingly. In some appraisal systems, for example, it becomes known that an "average" rating will not suffice for an average pay raise, and the rating given is thus inflated to the level anticipated to be necessary.
Measures for management decision are, in sum, "for keeps." Their semantics and pragmatics are communicated as much by the choices which are made in their light, as by their nominal pre-defined meanings. Behaviors in each of the three indicated roles play an important part in this adaptive process. The design of any MIS must necessarily anticipate these behavioral dimensions.

\section{CONCLUSION}

Measurement is typically an integral component of an MIS design. In our view, a theory of management information systems should thus include measurement among its elements. While measurement is common to today's MIS's, it is our observation that much is crudely done, reflecting a lack of sophistication with regard to the seven measurement aspects discussed above. When the student of MIS becomes a student of measurement as well, there is reason to hope that this deficiency may be remedied.

\section{REFERENCES}

1. Churchman, C. and Ratoosh, R. (Eds.) Measurement: Definition and Theories, John wiley, $(1967), 83-94$ !

2. Churchman, C. Suggestive, predictive, decisive and systemic measurements. Paper presented at the 2nd symposium on Industrial Safety Performance Measurement, National Safety Council, Chicago, December, 1968.

3. Churchman, $C$. The Design of Inquiring Systems, Basic Books, 1971 .

4. Kerlinger, F.N. Foundations of Behavioral Research, Second Edition. Holt, Rinehart and winston, 1973.

5. March, J.G. and Simon, H.A., Organizations, John Wiley, 1958.

6. Mason, R.O. and Swanson, E.B., Measurement for management decision: $A$ perspective. Cal i fornia Management Review, 21; 3, (Spring 1979) $70-\overline{8} 1$.

7. Mason, R.O. and Swanson, E.B., (Eds.) Measurement for Management Decision: Selected Readings, Addison-wesley, in press. 